mittee could, if need be, initiate studies where there are gaps in existing knowledge.

Considerable lip-service is paid to the importance of public health, but this will not be sufficient to maintain morale and to boost flagging recruitment in a branch of the profession which, on the evidence of Warren and Cooper's inquiry, is one with an age structure that can only give rise to anxiety. It might be' added that there are also grounds for believing that recruitment has also become unsatisfactory from the qualitative point of view, with the constant danger that a vicious circle could be established whereby indifferent staffing led to a content and a standard of work which were not in keeping with present and future requirements. Unless there is an early and penetrating official inquiry, with wide terms of reference, and unless this is followed by vigorous action, the service will inevitably fail to attract its fair share of the ablest medical graduates. Should this state of affairs come about, the resulting damage would extend far beyond the boundaries of public health, to affect the whole pattern and quality of medical care in this country.

\section{REFERENCES}

Brit. med. F. Suppl., 1967, 2, 10.

Ministry of Health (1963). The Field of Work of the Family Doctor. H M.S.O., London.

Reid, J. J. A.' (1964). Brit. med. f., 2, 1483.

(1965). Publ. Hlth (Lond.), 79, 183.

Warren, M. D., and Cooper, J.'(1966). Med. Offr, 116, 41.

\title{
SELF-HELP IN THE HOSPITALS
}

\section{Oxford Hospital Services Development Trust}

\author{
[From a Special Correspondent]
}

The Oxford Hospital Services Development Trust was established to raise money for improving the quality of service in the hospitals in Oxford. It was registered as a charity in 1965 and it already has $£ 12,000$ a year at its disposal. The Trust is concerned particularly to help those who need quick access to funds for urgent work. Any clinical or research work to be undertaken within the United Oxford Hospitals Group which would improve the quality of treatment or care of patients and which is in urgent need for extra resourceswhether they be equipment, drugs, grants, or even buildingsmay apply to the Trust for funds.

The idea for a voluntarily subscribed trust fund to supplement the State grant to the hospital group came from some of the group's medical staff-in particular Professor W. Ritchie Russell, whose energetic fund-raising had already provided the Oxford Hospitals with considerable extra facilities. In education it is well known that the school with an energetic parents' association can provide its pupils with many extra services. Similarly it is inevitable that hospitals want to develop faster than State funds can allow. This is possible only through other sources of money, of which voluntary contributions, particularly from local people, are a very important part.

The United Oxford Hospitals Group-which consists of two main hospitals (the Churchill and the Radcliffe) and several smaller units-is particularly in need of supplementary financial support. The Group fulfils two roles. Firstly, since the second world war it has been an undergraduate teaching hospital group. Secondly, the Group provides specialist services for the whole Oxford region covering a radius from Oxford of fifty miles. Nevertheless, the group has no large endowment fund like the older London teaching hospitals, most of which have large sums at their disposal. It is only by the most scrupulous budgeting that the Group can keep within its yearly allocation from the State. There is never enough money for all the new projects that research workers and other doctors want to carry out. Hunting for funds from other sources is so time-consuming that a research worker may well have left before his money has been allocated. Hence a permanent trust fund, devoted exclusively to the needs of the hospital group and quickly accessible, seemed the only answer to all of these problems.

\section{Setting up the Trust}

In setting up the Trust Professor Ritchie Russell and his colleagues first asked some of the leading laymen of Oxford to act as trustees. A small board of trustees was formed representing the major interests in the community-including industry, trade unions, the University, and the hospitals them- selves. The medical staff contributed about $£ 300$ to cover the administrative and legal costs of setting up the Trust and to start off the fund. Even before the Trust had been publicly inaugurated many local firms and private individuals had contributed a total of several thousand pounds. The public inauguration and a well-attended press conference ${ }^{1}$ have been the only organized publicity that the Trust has been given so far.

The money raised by the Trust is placed only in short-term investments. Professor Ritchie Russell pointed out that the Trustees needed to be able to get at the money when they needed it, rather than to save it all up. The continued existence of the Trust, therefore, depends on regular contributions from the people of Oxford, not just the usual once-and-for-all donation. Already most of the contributors have opted for subscriptions by deeds of covenant or bankers' orders. A particularly interesting type of contribution, moreover, is the weekly contribution of threepence being made by a high proportion of employees at Pressed Steel Fisher, Limited. Mr. M. A. H. Bellhouse, the Deputy-chairman of the company, is a Trustee, and through him the company has taken a particular interest in the Trust. $\mathrm{He}$ approached the unions with the idea that a small weekly deduction from each employee's pay packet might go towards the Trust. The response was highly favourable, and about half of the company's employees at all income levels have joined. the deduction scheme, despite the fact that they have to contract in to do so. Few employees have complained of having paid already for their hospital service through tax and insurance, and the Trustees hope that other industries and occupations in Oxford will contribute in the same way.

Another development has been that good will towards the Trust has been expressed not only in financial terms. Pressed Steel Fisher, Limited, helped the Department of Neurology at the Churchill Hospital to design and build new processing equipment for electroencephalographic records free of charge.

\section{Grants Already Made}

The Trust has already contributed money to several schemes. The first was a grant of $£ 10,000$ towards the building of a general practitioner maternity unit, the remaining $£ 20,000$ needed being raised elsewhere. The 14-bed unit, which adjoins the conventional maternity wards of the Churchill Hospital, is already in use. It accepts only normal births, and, though it was originally intended for confinements that otherwise would have occurred at home, it now accepts some first confinements as well. The unit is served by the same nursing staff as the 
adjoining maternity wards, but each patient in the unit is delivered by her own district midwife and is under the care of her own general practitioner. The unit is well designed and equipped, and is in great demand both by the local general practitioners and their patients.

The Trust has also paid for specialist $x$-ray equipment. One such piece of equipment, that allows the whole jaw to be photographed at once, was for the Medical Research Council Haemophilia Unit-which is attached to the Churchill Hospital. This grant by the Trust demonstrates very well how it can help where the State cannot. This is further exemplified by another grant the Trust has made for specialized $x$-ray equipment, this time for the Neurology Department of the Churchill Hospital. This equipment duplicates some of that already possessed by the Radcliffe Hospital, but before it was bought both patients and staff at the Churchill Hospital found it rather difficult to get to the department containing this equipment on the other side of Oxford.

The Trust has also recently contributed to the building of extra units for the Ear, Nose and Throat Department of the Radcliffe Infirmary. Dr. Gavin Livingstone wanted to build a day room for children (some of whose mothers had taken thalidomide during pregnancy) who come into hospital for six weeks or so for operations on the ear, many of them reconstructions of the external ear. For the greater part of their stay in hospital these children are up and about, and they needed somewhere to play. Dr. Livingstone obtained a generous donation from the Lady Hoare Thalidomide Foundation. This sum was not enough, however, particularly since he wanted to build other units as well, such as a day room, a diagnostic suite, and a small research laboratory. It was at this stage that the Oxford Trust came in. It awarded Dr. Livingstone $£ 1,000$, and, though this in itself was still not enough, it nevertheless gave extra encouragement to continue with fund-raising - and eventually the Lady Hoare Foundation and the regional hospital board were able to allocate the remainder of the money required.

How does the Trust decide which particular projects to support ? It takes no initiative itself, but a specialist subcommittee scrutinizes very carefully the applications for grants from research workers and others working within the hospital group received through the Board of Governors. If a donor to the Trust wishes his money to be spent in a certain way the Trustees try to carry out his wishes. The Trust also guarantees money to the hospital board for the board's own schemes on the condition that if the money turns out to be available from State funds the money from the Trust is not called for.

\section{Plans for the Future}

What are the Trust's future plans ? At present its founders are pleased to have got the scheme started-since this is the biggest hurdle-and to have it working smoothly even though on a relatively small scale. They are in no great hurry to speed up its activities excessively, though it is the policy to try to bring the Trust into the news every six months by the announcement, for example, of some new scheme that it is backing. At present the Trust's administrative machine is small, and it is administered almost entirely by people in their free time. Its secretary, for example, does his work for the Trust in his spare time, and administrative costs are therefore kept to a minimum. Similarly publicity has so far been on a small scale with the minimum of costs. Nevertheless, the Trustees feel that now that the Trust is working smoothly they can at any time boost it by a big publicity campaign aimed at letting all the people of Oxford know of its activities and needs. For example, Trustees might want to do this to finance a particularly big project, and by then they would be able to present concrete evidence of their achievements so far. As the Trust grows so will the amount of administration needed, and ultimately it will have to have a full-time office and secretary.

The Trustees have received many inquiries about the Trust from people outside Oxford, many of them interested in setting up similar trusts in their own districts. As Professor Ritchie Russell pointed out, it is very important when setting up such a Trust to come to terms with the local league of friends-who might well feel resistant to a scheme which appears to threaten their role. Thus in certain areas it might be possible to develop trusts out of the existing leagues of friends, provided they are prepared considerably to extend their terms of reference. There would be several advantages to this development-particularly since leagues of friends receive regular contributions from various sources, and have many contacts with other local organizations.

The Trustees of the Oxford Trust hope that other areas will set up similar trusts to help hospitals provide the special services that cannot be provided by the limited funds that are available from the State. They feel that other areas will find such a trust an extremely effective method of harnessing local good will on a basis of regular contributions. Another hope is that when a network of such trusts exists throughout the country healthy competition will arise between them, to the ultimate benefit of the entire hospital service in Britain.

REFERENCE

1 Brit. med. 7., 1965, 2, 773.
A Conference on Specialist Training in the National Health Service, organized by the Glasgow Postgraduate Medical Board, was held in the Royal College of Physicians and Surgeons of Glasgow from 27 to 29 April.

Opening the conference, the President, Professor J. H. Hutchison (Glasgow) said that the Royal College had not been content merely to set standards, but, in conjunction with the University of Glasgow, through the Postgraduate Medical Board had helped many young doctors to meet these standards. $\mathrm{Dr}$ J. H. F. Brotherston (Chief Medical Officer, Scottish Home and Health Department), speaking on "The Need," emphasized the strictly limited number of trained workers in the National Health Service and the difficulty of training future doctors while they were responsible for the care of patients. Training should be organized through national, regional, and local bodies, and a career guidance service was needed for all young graduates. The National Health Service-together with the colleges and universities-must be concerned with the future professional satisfaction of all graduates. Concluding, Dr. Brotherston said that more doctors were wasted by the failure to make effective use of women graduates than emigration. Women doctors were generally above the average both in capacity and performance, and part-time training posts and part-time work should be the rule rather than a miracle of contrivance and concession.

\section{The Objectives}

Sir JoHN McMichaEL (London) described the objectives of postgraduate training as the provision of facilities and support for the continuous development of knowledge and associated technical skills required for any branch of specialism in medicine. He emphasized the importance of example in bedside teaching - not so much of what to do but 